\title{
Standing on the Shoulders of Giants
}

\author{
Douglas Doucette
}

$\mathrm{H}^{2}$ aving recently completed my year as President of the Canadian Society of Hospital Pharmacists (CSHP), I joined dozens of others as a Past President of the organization. During this transition, I reflected on the Society's rich history and promising future as the Strategy Towards Sustainability is being implemented (https://www.cshp.ca/strategy-towards-sustainability). Mirroring George Bailey from the movie It's a Wonderful Life, I wondered what our practice would look like if CSHP did not exist!

CSHP was formed by the coming together of numerous regional associations of hospital pharmacists and has evolved over decades into today's national professional association. The shared values and goals of our members bind us together, giving us a community with common purpose. Many who have motivated me in my career have been leaders of CSHP, as well as pharmacy directors, managers, front-line practitioners, residents, and students. CSHP members have been trailblazers with their individual achievements and collective accomplishments. It is unlikely that our profession would be as prominent within healthcare institutions without a national association to support our efforts.

The Society's greatest asset is its members: the circle of pharmacists, residents, students, and pharmacy technicians from hospitals, clinics, primary and home care settings, academia, and industry. Members are supported by the Board, National Office, affiliated boards, Foundation, Branches, and committees-all of which support the execution of our initiatives and work to generate benefits for members. I am grateful for the expertise of members who have built CSHP to operate as an effective national association. Our Society is strengthened by all Branches as they project our shared values within their respective provinces and their leaders contribute to the national direction of the Board, committees, task forces, and PSNs (Pharmacy Specialty Networks). Our members are the heart and soul of CSHP, and they support our efforts from coast to coast to coast.

CSHP has fostered excellence and innovation in patient care throughout its history. While pharmacists would achieve practice excellence in the absence of a professional association, CSHP has enabled a more rapid spread and uptake, facilitating dialogue of what excellence is and should be. CSHP's position statements, guidelines, and other publications provide direction to hospital pharmacy practice with a

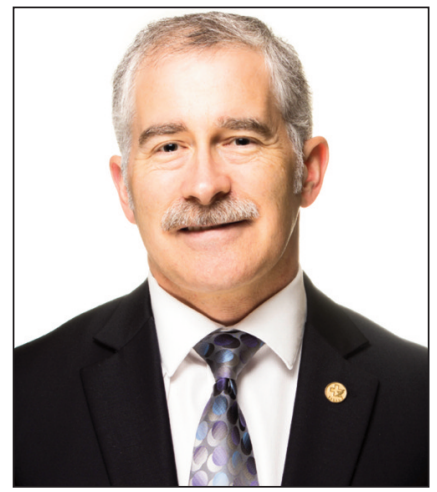
unique Canadian perspective. Would CSHP 2015 or the Excellence in Hospital Pharmacy initiatives have existed without CSHP? While pharmacy conferences and seminars are organized in all regions of Canada, CSHP continues to sponsor events with high-calibre content and speakers of national and international expertise. Residency programs are accredited through the Canadian Pharmacy Residency Board, facilitating the development of national standards and advanced training for young leaders and clinicians. The Canadian Journal of Hospital Pharmacy is a respected publication providing authors with the opportunity to share their knowledge and work in pharmacy practice, adding to the body of knowledge on how best to provide safe and effective patientcentred care.

Some readers may think this commentary is stating the obvious, but that is all the more reason to reflect on what makes CSHP a relevant, dynamic professional association. Like George Bailey, let's not take for granted our past accomplishments. We owe a debt to those who have come before us and on whose shoulders we have stood in the advancement of our profession.

Douglas Doucette, BSc(Pharm), PharmD, FCSHP, is Past-President and External Liaison for the Canadian Society of Hospital Pharmacists. 